\title{
THE IMPACT OF LEGO MINDSTORMS NXT ROBOT IN SCIENCE ON SIXTH GRADE STUDENTS IN BAHRAIN
}

\author{
Dr. Minimol Anil Job ${ }^{1}$, Hasna'a Jaffer Mohammed Al Saeed ${ }^{2}$ \\ ${ }^{1}$ Assiatnt Professor, ITC Department, Arab Open University, Kingdom of \\ Bahrain \\ ${ }^{2}$ ITC Teacher, Al-Andalus Primary Girls School, \\ Ministry of Education, Kingdom of Bahrain
}

\begin{abstract}
This research was conducted to gather information about the impact of usingLEGO MINDSTORMS NXT ROBOT in science on sixth grade students in primary schools, the need ofit in education, its advantages, disadvantages, hardware and software used to develop it and whether it fits with the physiological and cognitive developments characteristics of the students. The participants attended a LEGO robotic training programin three science experiments to study the motion, distance and speed principles. The researchers applied a science test, a student's questionnaire, a teacher's interview and a teacher's interview scale to gather the needed information. The results show that the LEGO robot is an efficient technology in teaching science, increases the students' academic achievement as the science test results show and the findings emphasize that this robot is a valuable technology in education and in primary schools as it develops the 21st century skills of the students.
\end{abstract}

\section{KEYWORDS}

Robot, Lego Mindstorms NXT Robot,Critical Thinking, Mindtool

\section{INTRODUCTION}

Educational field is one of the primary fields that benefits from new technologies. As we see in many countries education becomes rich of effective technologies. For example, in Bahrain, the big project, King Hamad Project for Future Schools, which was launched by Ministry of Education in 2004, opened the door for education in Bahrain to use new technologies (Smart board, Attractive board, Data Show, Camera....etc.) in order to use ICT in the learning process[1]. The learning process changes day by day, new strategies and new words come up such as collaborative learning, problem-solving strategy, students learning style...etc. Each of these strategies needs to use technological tools. So, as a new technology in education within these new strategies, it is the chance to enter the world of robotics as a new door for an attractive ICT tool in education in Bahrain. The researchers searched about using robotics in education and 
Computer Science \& Information Technology (CS \& IT)

found many exciting and successful experiments and studies about using the educational LEGO MINDSTORMS NXT ROBOT for teaching students' mathematics and science principles and how it is effective in problem-solving, creative thinking and critical thinking strategies [2] [3].LEGO Mindstorms is a line of programmable robotics/construction kits, manufactured by the Lego Group (LEGO Education, 2011). Lego Mindstorms is primarily used in secondary education but most universities also use the Lego Mindstorms NXT for their introductory courses in mobile robotics or for projects. There is now a new Lego Mindstorms Robot, called the EV3.In this research, the researchersused the Lego Mindstorms NXT 2.0 (8547), the second set from LEGO's Lego Mindstorms. The set contains 619 pieces, including a new sensor that can detect colors [4]. It provides students to control the behavior of a tangible model by means of a virtual environment and conduct science experiments, in which young students investigate a socio scientific issue using their scientific process skills both in and out of the classroom[5]. The aim of using this set is to study its impact in science on sixth grade students in primary schools in Bahrain.The aim of this research is to know more about robotics and the educational Lego Mindstorms NXT robot.What is the impact of using it in teaching science at sixth grade students? What are the advantages and disadvantages of using robotics in education? Does robotics fit with the physiologies and cognitive developments characteristics of sixth grade students? What are the software and hardware needed to apply this technology? Can Bahrain schools apply it or not?

\section{OBJECTIVES OF THE STUDY}

The objectives of this researchare to know the different types of robots, to identify the impact of educational Lego Mindstorms NXT robot in science classes of sixth grade students, to emphasize the advantages and disadvantages of robotics in schools, to know how robotics fit with the physiological and cognitive developments characteristics of sixth grade students and to know the software and hardware needed to use educational robotics in schools.

\section{SIGNIFICANCE OF THE STUDY}

The word "robot" expresses the relationship between the child and the games, especially[6][7]. It is seen as a new educational object that causes advanced teaching and the growth of kids. The robot role is seen as an educational tool that encourages students at all levels (Primary, Intermediate and Secondary) to study science. It is also noticed that the students are guided to study the principles of programming and engineering. Most of the students try to collect robots and program them to do a specific task. So, it opened up doors to the students to create, and apply scientific principles[8].Consequently, the importance of directing students to use the robot in the learning process can be summarized in the following points:

- Student participation in the educational process (Student-Centered learning process).

- Teaching the principles of science and mathematics through experimentation.

- Learn programming through programming the robot in order to perform a specific task.

- Develop problem-solving skills by building and programming the robot.

- Spark student's interest in Science and Technology. 


\section{REQUIREMENTS SPECIFICATIONS}

The robot that used in this research is built using the LEGO Mindstorms NXT 2.0 (8547) kit which contains an intelligent NXT Lego brick with 32-bit microprocessor and a large matrix display, three interactive servo motors; four sensors (Ultrasonic Sensor, 2 Touch Sensors and the all-new Color Sensor).The color sensor has triple functionality: distinguishes color and light settings, and function as lamp [9][10]. The software that will be used in this research is the MINDSTORM Software which lets the user to program the robot. The software is used to create a program, and then it is downloaded to the NXT by using the USB cable or the wireless Bluetooth connection. Mac- and PC-compatible drag- and- drop software gives the user 16 building and programming challenges, from beginner to expert [11][12].The researchers used as hardware the laptops with Microsoft Windows 7 to program the robot as well as the data show and the Smart board to display the work of the students.

\section{RESEARCH METHODOLOGY}

The researchers found that the MINDSTORM NXT robot is suitable for primary schools students as they can build it easily using the Lego parts to design it according to the function they want it to perform. Besides, this type of robot comes as a kit with a software CD that has the LEGO NXT-G programming language, a graphical language understandable by the small students[13] [14].First, we built the robot by hand programmed it using the NXT-G programming language software and tested it. Then it is tried it in the school with four sixth grade students.After receiving approval from the higher authority to apply this tools and the application on Bahrain government's schools, the researchers prepared the research tools which are questionnaire for students, interview questions for teachers, interview scale for the teacher interview and a science test for the students in two languages in Arabic and English. At first the researchers introduced the concept and objectives of the research to the science teacher then applied the LEGO training program and science experiments in motion, distance and speed on a group of six sixth grade students which is the experimental group and the other 6 students. The control groups have not attended the training program and they studied motion, distance and speed by the regular methods. The researchersused two laptops; one of them connected to the data show and used most of the time by the researchers. The other laptop used by the students for programming and designing instructions. The researchers asked some teachers to attend the training program and the science lessons to see the application of the LEGO Mindstorms NXT robot in science [15][16]. The researchers then applied a summative evaluation test on groups, the experimental and the control groups. The questionnaires were distributed to the experimental group students and interviewed the teachers who intended the training program and the science lessons. Also, the researchers will ask the teachers to fill the interview scale. The information that collected from student's questionnaire, teacher's interview, teacher's interview scale is used for the data analysis both quantitative descriptive. The analysis has done using both Microsoft Excel and SPSS.

\section{Study Population ANd SAMPling PROCEDURE}

The total sample is 12 students in one primary school from sixth grade class divided into two equal groups, each group has 6 students. One group is an experimental group and the other is a control group. The sample is non-homogeneous since the students are differentiating in learning style and academic achievements. The sample of this research is a probability sample. 


\section{a. LEGO Training Program and Science Experiments}

Since the students of the experimental group don't know about this robot before, the researchers will conduct a training program on LEGO Mindstorms NXT robot to make the students familiar with this robot and to develop their skills in designing and programming it to achieve a specific task before starting using it in the science lessons and experiments. The training program was a robotic curriculum prepared by the milset ASIA (the International Movement for Leisure Activities in Science and Technology) which was established on July 1987 in Kuwait ("Milset ASIA," 2014). This training program was applied before on Kuwait intermediate and primary schools as an activity program during the students' free times. The researchers scheduled one week training program divided into two classes' everyday as described in the table below.The students have taken works as one team with the defined rules; Engineer (builder) - 2 students, Software Specialist (programmer)-2 students, Information Specialist (Gets the necessary information for the team to move forward) - 1 student and Project Manager (Whip-cracker) - 1 student.

\subsection{Science Experiments}

After the application of the LEGO robot training program, the students designed the robot as a simple vehicle according to the design guideline embedded within the LEGO Mindstorms NXT2.0 software and it comes as a manual with the LEGO kit and the robot used for applying the science experiments to learn the scientific principles in motion, distance and speed. In each experiment, the students programmed the robot using the NXT-G programming language according to the rules given and observed the results and record the data. Finally, they deduced the science principle learned from the experiment.The researchers applied three experiments. The first experiment is about the linear motion in which the students will use the robot to know the definition of a motion, the meaning of the start and end points and to understand what a linear motion is by programming the robot to move forward in a straight line at a given time. That is to integrate technology with science. The experiments can be summarized by follows:

\section{Experiment\#1: Linear Motion}

The goals of this experiment are to know the definition of the motion, to know what a start point and an end point are and to understand the linear motion. Also, its goal is to improve the robot designing skills of the students. The team will design a robot in the shape of a vehicle and they program it to move forward at a given time. Then, they will define the start point and the end point of the robot motion and deduce what type of motion the robot moves with.

\section{Experiment\#2: Distance Measurement}

The goals of this experiment are to measure the distance that a robot passes, to improve the student skills in designing and programming the robot to pass a certain distance in addition to improve the robot designing skills of the students. The team will specify a start point for the robot movement and the end point where the robot stops and they will measure the length of the track between these two points. They should conclude that the distance is the total length of a track between two points and it is measured in meters. 


\section{Experiment\#3: Speed}

This experiment consists of two parts. The first part goals are to calculate the speed of the robot by measuring the distance it passes within a given time and to explain the relationship between the power, the distance and the speed by programming the robot to move forward with a predefined power of the motors where the students change the power three times and measure the distance and then calculate the speed of the robot. The second part of this experiment is similar to the first part. However, it aims to know the time needed for the robot to pass a known distance, to calculate the speed and then explain the relationship between the time and the speed. In this experiment, the students should know the unit used to measure the time.

\section{DAta Collection Procedures}

The researchers collected quantitative information from the test and the students questionnaire which applied on the students, and the teachers interview scale which answered by the interviewed teachers and the researchers collected the qualitative information from the teacher's interviews answers, teacher's interview scale, and the test results. In addition, the researchers collected qualitative information from the observations in control and experimental groups about student's reaction in the learning process in the lessons that the robot used for teaching.

\section{DATA ANALYSIS AND RESUltS}

\section{a. Analysis of Personal Demography of the Student Test}

This part contains the analysis of the student's test sample demography, which are age, and academic achievements of students in marks. The test was done by the experimental and control groups. Each group had 6 students. The total number of the test sample was 12 students, $67 \%$ of the students were 11 years old and $33 \%$ of them are 12 years old. This means that all the students in the experimental and control group are within the age of sixth grade students according to the Ministry of Education.According to the final average achievements of the science test for the first and second terms of the year 2013/2014, 50\% of the students got marks between 100-90 which is A grade, $17 \%$ of the students got marks between $89-80$ which is B grade, $8 \%$ of the students got marks between 79-70 which is $\mathrm{C}$ grade, $8 \%$ of the students got marks between $69-60$ which is $\mathrm{D}$ grade and $17 \%$ of them got marks less than 60 which is $\mathrm{F}$ grade.

\section{b. Analysis of Student's Questionnaire}

The questionnaire of the students consists of three major sections, which were: learning objectives, learning process and LEGO-robot efficiency and it had two open questions. The questionnaire was answered by the experimental group students. The total number of the students was6 and all the questionnaires are accepted.

\section{c. Analysis of the Learning Objectives}

The mean values of the responses of the questions were between 4.67 and 5.00, the highest mean was 5.00 which states that the LEGO-robot helped me to know the relationship between the distance,the time and the speed and the participants agreed that LEGO-robot helped them to explain the relationships between the power and the speed, to know the definition of a motion, to 
know the definition of a distance, to know what a start point is and also to know what an end point is and to calculate the speed of an object.

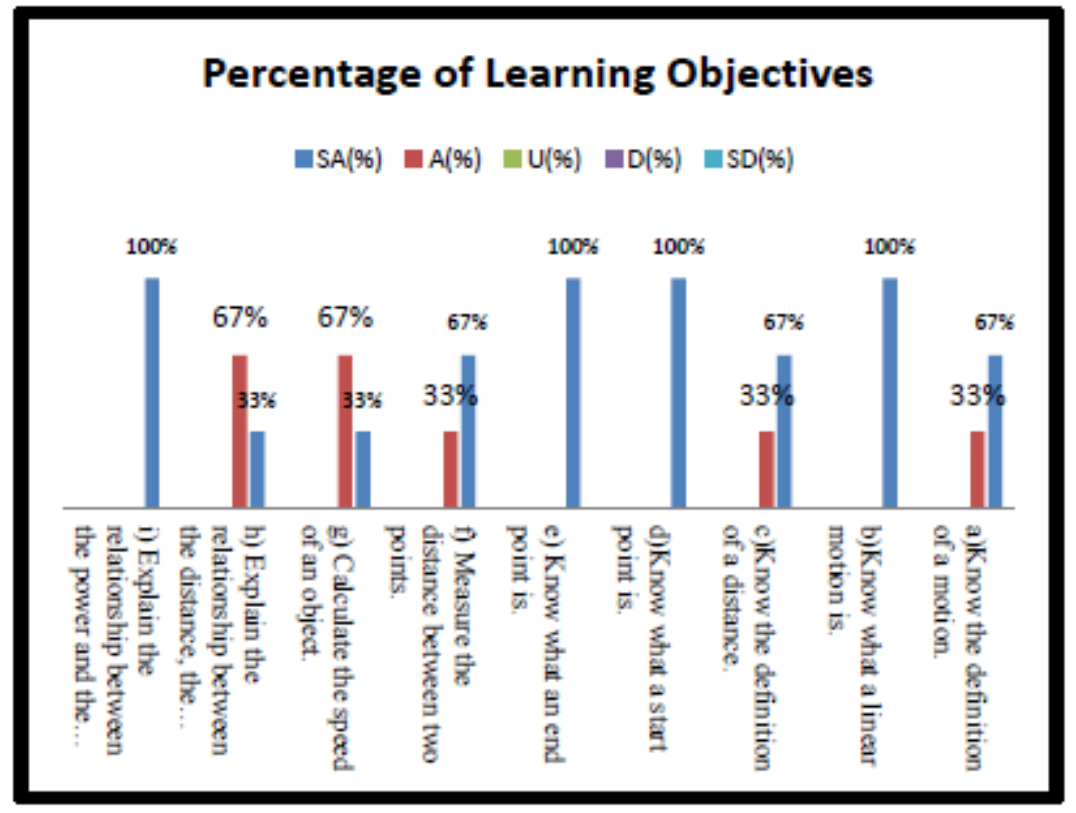

Figure 1: Percentage of the LEGO-robot Efficiency Section in the Teacher's Interview Scale

\section{d. Analysis of the LEGO-robot Efficiency}

The mean values of the responses of the questions were between 1.17 and 5.00, the highest mean is 5.00 which states that the programming of the LEGO-robot was easy, the technology used (hardware and software) to build the LEGO-robot was adequate and the use of LEGO-robot need to know some computer basics, they we need to use LEGO-robot in future to learn other science basics and the programming language used to program the LEGO-robot was understandable. All the participants agreed that the design of the LEGO-robot was difficult and it is not just a toy.

\section{Programming of The Science Experiments}

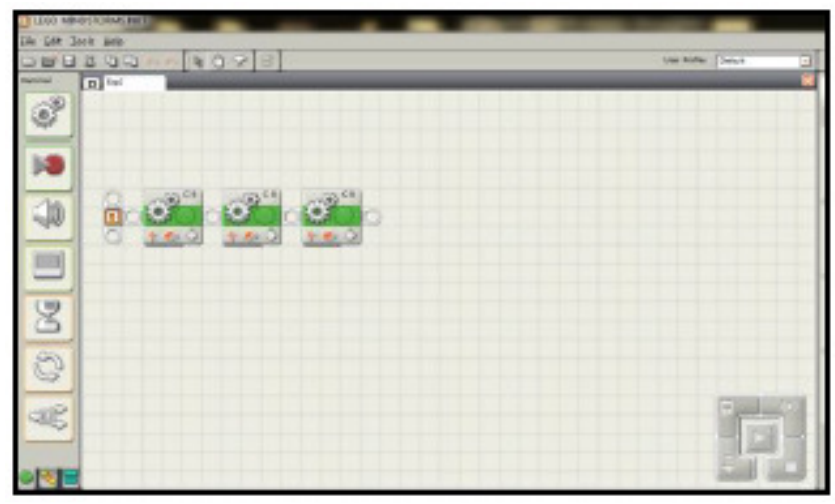

Figure 3: (Exp-1) Programming the LEGO robot to move forward for 3 rotations 
Figure 3 shows the programming interface of the first experiment, where the student should programs the robot to move forward (as clear in the move block) for a given time, and in this experiment, the time is given as three rotations which is clear in the (Duration) part.

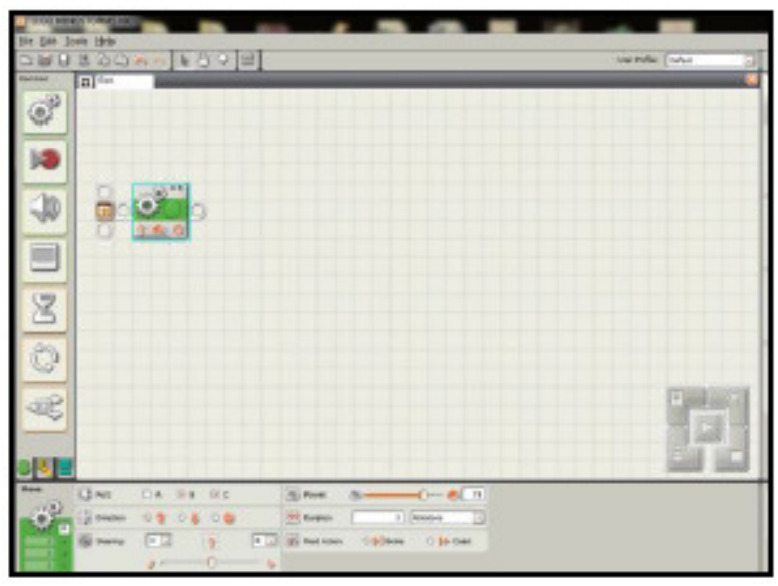

Figure 4: (Exp-2) Programming the LEGO robot to move forward three times with different durations

Figure 4 shows the programming interface of the second experiment, where the student should programs the robot to move forward from point $\mathrm{A}$ to point $\mathrm{B}$ for 10 seconds, then move it forward again from point $\mathrm{B}$ to $\mathrm{C}$ for 7 seconds, and finally move it forward from point $\mathrm{C}$ to $\mathrm{D}$ for 10 seconds.

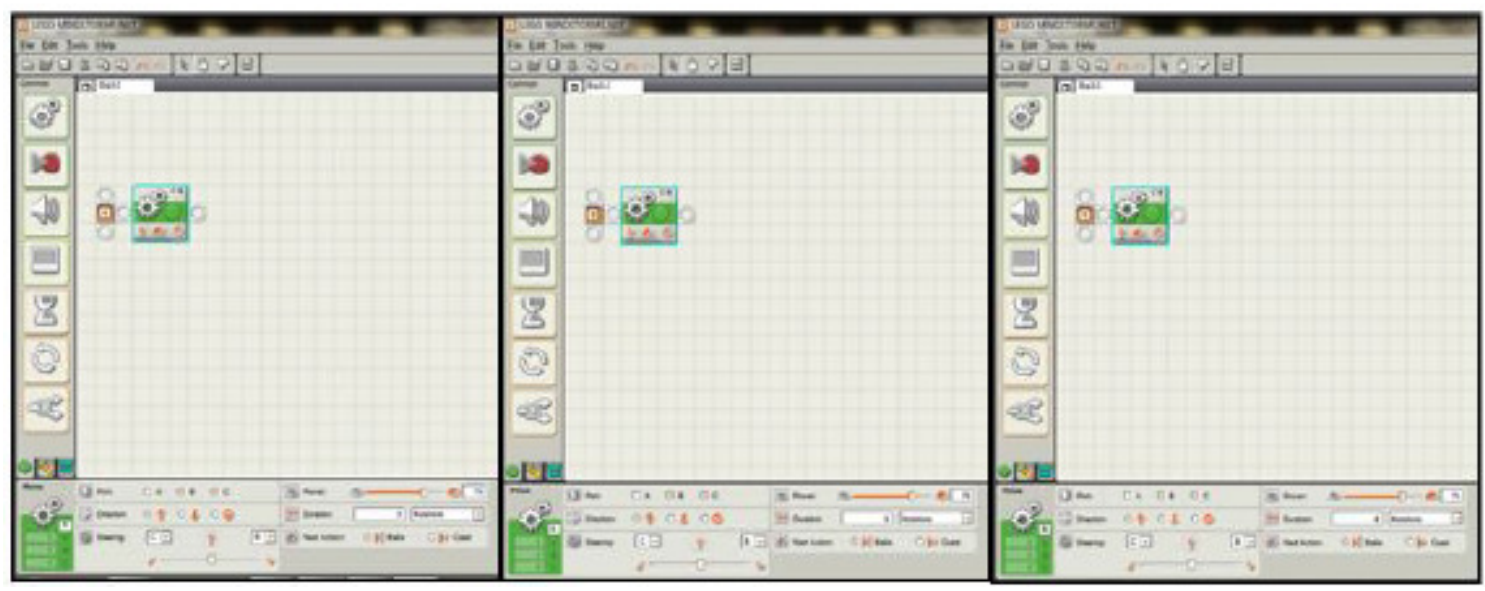

Figure 5: (Exp-3-1) Programming the LEGO robot to move forward three times with different powers for 10 minutes each time

Figure 5 shows the programming interface of the first part in the third experiment, where the student should programs the robot to move forward using different powers for three times, and she should change the power in each time. The power of the robot should be 50 at the beginning, then it should be changed to 75 and finally it should be changed to 100 . 


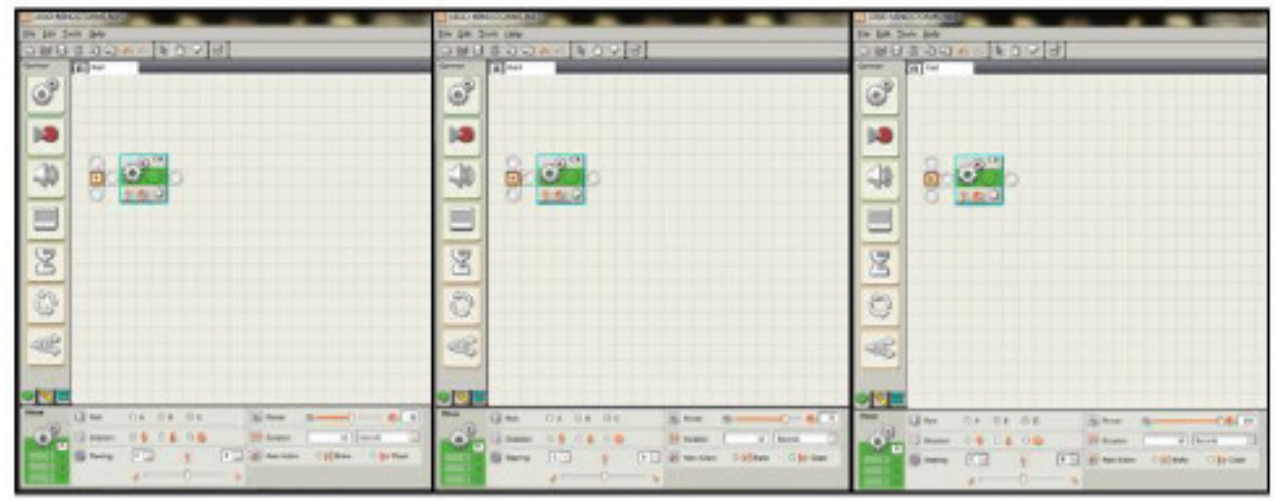

Figure 6 :(Exp-3-2) Programming the LEGO robot to move forward three times with different durations using different numbers of rotations

Figure 6 shows the programming interface of the second part in the third experiment, where the student should programs the robot to move forward using different numbers of rotations three times, and she should change the number of rotations in each time. The duration of the robot should be 3 rotations at the beginning, then it should be changed to 5 and finally it should be changed to 8 .

\section{DISCUSSION}

The researchers conducts this research to determine the needs for the LEGO robots in primary schools, determine the advantages and disadvantages of using it in schools, how it fit with the physiological and cognitive development characteristics of sixth grade students, what are the softwares and the hardwares needed to build and program these robots and to determine whether Bahrain schools can apply it or not.

\section{a. Research Findings and Conclusion}

The key findings that the researchers collects from applying the LEGO MINDSTORMS NXT ROBOT, to collect information about the impact of using it in science on sixth grade students are:

- A robot is a machine used to perform jobs automatically, which is controlled by a computer, the basic parts of a robot are: sensors, effectors, and control system.

- The robots canbe divided into different types according to their applicationsas the following : industrial, household, medical, service, military, entertainment, hobby and copetition, and educational robots.

- LEGO MINDSTORMS NXT ROBOT is an educational robot that comes as a kit consists of different parts. The hardware of this robot consists of NXT brick, 619 lego parts, three interactive servo motors, and four sensors (2 touch sensors, 1 color sensor, 1 ultrasonic sensor) and the software is the LEGO MINDSTORMS NXT software that uses the NXT$\mathrm{G}$ programming language. 
- The LEGO robot is needed to use in education and in primary schools since, it fit with the new generation's requirements and fit with the 21th century learning skills ( learning, literacy and life skills) as it improves the technology literacy and makes the students technology friendly, it develops the learning skills by improving the critical thinking, creative thinking, collaboration and communication of the students and it also improve the students' life skills in flexibility and leadership as they can manage the work of the team and learn independently.

- The advantages of the LEGO robot are: the flexibility in designing it in different shapes, easy to build and program, the cost of the kit as it can be bought by the students to continue practicing at home, its robust material and projects, the graphical interface of NXT-G programming language.

- The disadvantages of the LEGO robot are logistical, they are: cost of providing one robot for each student is expensive, the sensors problems, lost or damage of the lego parts and the problems with the power of batteries.

- The pedagogical theory that the LEGO robot fit with is: constructionism.

- The psychological theory that the LEGO robot fit with is: cognitive theory where the LEGO robot is suitable to be a mindtool.

\section{RECOMMENDATIONS}

The researchers recommends the following ideas for future works:

- To organize a robotic camp to study the impact of using the LEGO robot in STEM education by the participation of different STEM ( science, technology, engineering and mathematics ) teachers.

- To conduct a future research to evalute the effects of robotic activities on children's social skills.

- To use the LEGO robot to teach other subjects such as Computer, Maths, Physics, Art and English.

- To use the LEGO robot for different education stages, primary, intermediate and the secondary stages.

- To conduct a research to study the impact of using the LEGO robot with other smart technologies such as smartphones and IPads.

- To use the LEGO robot for further advanced research with smartphones to scan qr codes 


\section{REFERENCES}

[1] Alimisis, D., Moro, M., Alergui, J.,Pina, A., Frangou, S.\&Papanikolaou, K. (2007). Robotics and Constructivism in Education: the TERECoP project. euroLogo 2007 Bratisiava

[2] American Heritage Dictionary. (1995). http://americanheritage.yourdictionary.com/

[3] Barker, B. S., \& Ansorge, J. (2007). Robotics as means to increase achievement scores in an informal learningenvironment. Journal of Research on Technology in Education, 39(3), 229-243.

[4] Benitti, F. B. V. (2012). Exploring the educational potential of robotics in schools: A systematic review. Computers \& Education, 58(3), 978-988.

[5] Chambers, J. M., \& Carbonaro, M. (2003). Designing, developing, and implementing a course on LEGO robotics for technology teacher education. Journal of Technology and Teacher Education, 11(2), 209-241.

[6] Christmas, M., Hanukkah, H., Kwanzaa, H. (2014). Educational Robots, Retrieved from: www.robots-and-androids.com/educational-robots.html

[7] Cocek, C., C. (2008). Lego Mindstorms and Critical Thinking Skills in the Elementary Classroom. Mount Saint Vincent University, p.12

[8] Framework for 21st Century Learning. (2011). Retrieved from: www.p21.org/our-work/p21-framework

[9] Jonassen, D. H. (2000). Computers as mindtools for schools. NJ: Prentice Hall.

[10] Kelly, J. (2010). LEGO MINDSTORMS NXT-G Programming Guide (Second Edition). USA, P1

[11] Korkmaz, O., Altun, H., Usta, E., \&Ozkaya, A. (2014). THE EFFECT OF ACTIVITIES IN ROBOTIC APPLICATIONS ON STUDENTS' PERCEPTION ON THE NATURE OF SCIENCE AND STUDENTS' METAPHORS RELATED TO THE CONCEPT OF ROBOT. International Journal on New Trends in Education and Their Implications. 5 (2). Article: 05 . ISSN: 1309-6249

[12] Lego Mindstorms NXT Hardware Developer Kit. (n.d.). Retrieved May 30, 2014, from http://mindstorms.lego.com/en-us/support/files/default.aspx

[13] Milset ASIA. (2014). Retrieved from: www.milset.org/en/regions/asia.html

[14] Ruiz-del-Solar, J., \& Aviles, R. (2004). Robotics Courses for Children as a Motivation Tool: The Chilean Experience. IEEE Transactions on Education, 47(4), 474-480. doi:10.1109/TE.2004.825063

[15] UCGUL, M. (2013). Hstory of Educational Potential of LEGO Mindstorms NXT, Mersin University Journal of the Faculty of Education. 9(2) pp.127-137

[16] Williams, D., Ma, Y., Prejean, L., \& Ford, M. (2008). Acquisition of Physics Content Knowledge and Scientific Inquiry Skills in a Robotics Summer Camp, Journal of Research on Technology in Education, 40(2), 201-216 